\title{
ИСПОЛЬЗОВАНИЕ МОНОКЛОНАЛЬНЫХ АНТИТЕЛ ДЛЯ ТЕРАПИИ АУТОИММУННЫХ ЗАБОЛЕВАНИЙ
}

\author{
Е. М. Мерзляк ${ }^{1,2} \bowtie$, Д. С. Сыркоㄹ, Е. А. Мусаткина², М. Израельсон ${ }^{1,2}$ \\ ${ }^{1}$ Институт биоорганической химии имени М. М. Шемякина и Ю. А. Овчинникова Российской академии наук, Москва \\ ${ }^{2}$ Научно-исследовательский институт трансляционной медицины, \\ Российский национальный исследовательский медицинский университет имени Н. И. Пирогова, Москва
}

\begin{abstract}
В последнее время в терапии аутоиммунных заболеваний стали активно применять моноклональные антитела (МА). Мишенью этих антител служат провоспалительные цитокины и собственно Т- и В-клетки, потенциально участвующие в патогенезе заболевания. В данной статье сделана попытка систематизировать используемые препараты и привести основные механизмы, лежащие в основе такого рода терапии, описаны нежелательные побочные действия. Потенциальными путями и перспективами развития биологиксов в лечении аутоиммунных заболеваний, по нашему мнению, являются МА, которые узнают и элиминируют клоны Т- и В-клеток, обусловливающие патогенез аутоиммунного заболевания. Поиск аутореактивных клонов является одной из сложных и актуальных задач современной биомедицины.
\end{abstract}

Ключевые слова: аутоиммунные заболевания, биологиксы, терапевтические антитела для лечения аутоиммунных заболеваний, механизм действия моноклональных антител

Финансирование: работа выполнена при поддержке Минобрнауки России (идентификатор соглашения RFMEFI60716X0158).

$\triangle$ Для корреспонденции: Екатерина Марковна Мерзляк

ул. Миклухо-Маклая, д. 16/10, г. Москва, 117997; ekaterin99@mail.ru

Статья получена: 06.12.2018 Статья принята к печати: 20.12.2018

DOI: $10.24075 /$ vrgmu.2018.094

\section{THE USE OF MONOCLONAL ANTIBODIES IN AUTOIMMUNITY TREATMENT}

Merzlyak $E M^{1,2} \otimes$, Syrko $\mathrm{DS}^{2}$, Musatkina $\mathrm{EA}^{2}$, Israelson $\mathrm{MA}^{1,2}$

'Shemyakin-Ovchinnikov Institute of Bioorganic Chemistry, RAS, Moscow

${ }^{2}$ Research Institute of Translational Medicine,

Pirogov Russian National Research Medical University, Moscow

Recently, monoclonal antibodies (MA) have gained popularity as therapeutic agents for the treatment of autoimmune disorders. These antibodies target proinflammatory cytokines, as well as $\mathrm{T}$ and $\mathrm{B}$ cells potentially involved in the pathogenesis of such conditions. In the present work we attempt to give a systematic description of available therapeutic MA, highlight their key mechanisms of action and pinpoint their adverse effects. We believe that MA that are capable of recognizing and eliminating pathogenic T- and B-cell clones hold the most promise for medical application as biologics. Detection and identification of autoreactive lymphocyte clones is one of the most serious challenges of contemporary medicine.

Keywords: autoimmune disorders, biologics, therapeutic antibodies for autoimmunity treatment, mechanism of action of monoclonal antibodies

Funding: this work was supported by the Ministry of Science and Higher Education of the Russian Federation (ID RFMEFI60716X0158).

$\triangle$ Correspondence should be addressed: Ekaterina M. Merzlyak

Miklouho-Maclay, 16/10, Moscow, 117997; ekaterin99@mail.ru

Received: 06.12.2018 Accepted: 20.12.2018

DOI: $10.24075 /$ brsmu.2018.094

По мере углубления наших знаний о природе адаптивного иммунитета, формируются представления о тех ключевых точках, в которых может происходить сбой работь иммунной системы, приводящий к развитию аутоиммунных заболеваний. Спектр аутоиммунных расстройств крайне широк и затрагивает практически все ткани организма. Патогенез этих заболеваний обусловлен как появлением аутоиммунных антител, так и размножением эффекторных Т-клонов, узнающих собственные антигены и, как следствие, провоцирующих воспалительные процессы, в отдельном органе или в целой системе. Аутореактивные Т-клоны могут присутствовать в крови и здоровых доноров [1], но находятся в состоянии иммунологической толерантности - анергии, контролируемой регуляторными
Т-клетками (Tregs). Нарушение численности Tregs или их функциональной активности наблюдается при многих аутоиммунных заболеваниях и может служить одной из причин развития воспалительных процессов.

На сегодняшний день для лечения аутоиммунных нарушений применяют подходы, которые обеспечивают общую иммуносупрессию за счет препаратов, напрямую или косвенно снижающих воспаление (рис.). В данной работе рассмотрены виды терапии аутоиммунных заболеваний с применением моноклональных антител (МА). В англоязычной литературе такие МА вместе с другими генно-инженерными препаратами для клинических целей получили название «биологиксы». Целый ряд МА эффективно применяют для лечения разных аутоиммунных 
заболеваний. Многие препараты еще находятся на стадии клинических испытаний.

Терапевтические МА могут значительно различаться по способу действия. Они могут связываться с растворимым лигандом, ингибируя его активность, или с рецептором на мембране клетки-мишени, блокируя взаимодействие рецептора с лигандом, модулируя поступающий через этот рецептор сигнал или вызывая апоптоз (рис.).

Механизм деплеции целевой популяции клеток с помощью MA различен. Деплеция, обусловленная FCфрагментом антитела, может вызывать апоптоз целевой клетки, гибель клетки по механизму антителозависимой или комплементзависимой цитотоксичности (ADCC/CDC), либо антигензависимый фагоцитоз. Принципиально иные механизмы запускаются при блокировке поверхностных костимуляторных рецепторов, что приводит к отсутствию сигнала в ответ на стимуляцию антигеном, либо к «перепрограммированию» эффекторных Т-клеток в Tregs.

Ремиссии при терапии, приводящие к снижению уровня воспалительных цитокинов (IFNy, TNF, IL17 и т. п.) или экранированию рецепторов цитокинов, носят временный характер и зависят от скорости выведения терапевтического антитела. Подходы, основанные на деплеции популяции, обогащенной аутореактивными Т-клетками, нам кажутся наиболее перспективными, так как устраняют причину заболевания. Внимания заслуживает также стратегия функциональной активации регуляторных Т-клеток, ведущая к увеличению экспрессии супрессорных цитокинов (IL10).

\section{Общие представления о структуре терапевтических антител и их применении}

За последние несколько лет значительно расширился список терапевтических антител, относящихся к препаратам, модифицирующим течение заболевания (DMT) и обладающим селективным механизмом действия. Около 40 МА одобрено Управлением по контролю качества продуктов питания и лекарственных средств CША (FDA) для лечения различных заболеваний, в том числе аутоиммунных.

Как правило, первично полученные МА требуют дальнейшей оптимизации. Существуют разные стратегии оптимизации антител: модификация Fc-фрагмента для увеличения времени полужизни антитела, гуманизация (т. е. введение аминокислотных замен, которые делают антитела похожими на человеческие для снижения риска иммунного ответа на вводимый препарат), наработка антител в специализированных клеточных линиях, десицитных по ферментам гликозилирования для усиления цитотоксических свойств. Так, терапевтические нефукозилированные антитела обладают в 500-1000 раз более высокой цитотоксичной активностью, чем такие же антитела с высокой степенью гликозилирования [2]. В последнее время в литературе обсуждается вопрос об использовании антител с нарушенным Fс-фрагментом, так как при гибели большого количества эффекторных клеток (например, при использовании антител к поверхностным маркерам, которые представлены на широком спектре клеток) наблюдается выброс воспалительных цитокинов, приводящий к проявлению широкого спектра неблагоприятных побочных реакций.

\section{Моноклональные антитела против цитокинов и факторов воспаления}

Первыми MA, одобренными FDA для лечения воспалительных заболеваний, в основном аутоиммунных (2002 г.), были препараты, содержащие МА к фактору некроза опухоли (ФНО). За последнее время список терапевтических мишеней пополнился целым рядом цитокинов (такими как IL1, IL6, IL12, IL15, IL17, IL18 и IL23), ассоциированных с патогенезом аутоиммунных заболеваний. Эффективность этих препаратов в отношении различных аутоиммунных заболеваний подробно описана в ряде обзорных работ $[3,4]$.

ФНО является одним из первых индукторов воспаления в цитокиновом каскаде, поэтому при использовании ингибиторов ФНО можно наблюдать неспецифическое снижение воспалительных реакций у пациентов, страдающих аутоиммунными расстройствами (ревматоидный артрит (РА), анкилозирующий спондилит, псориаз, болезнь Крона и др.). На сегодняшний день доступно четыре препарата МА к ФНО, отличающиеся степенью гуманизации и сайтом посадки МА (инфликсимаб, голимумаб, цертолизумаб, адалимумаб). Данные препараты широко используются

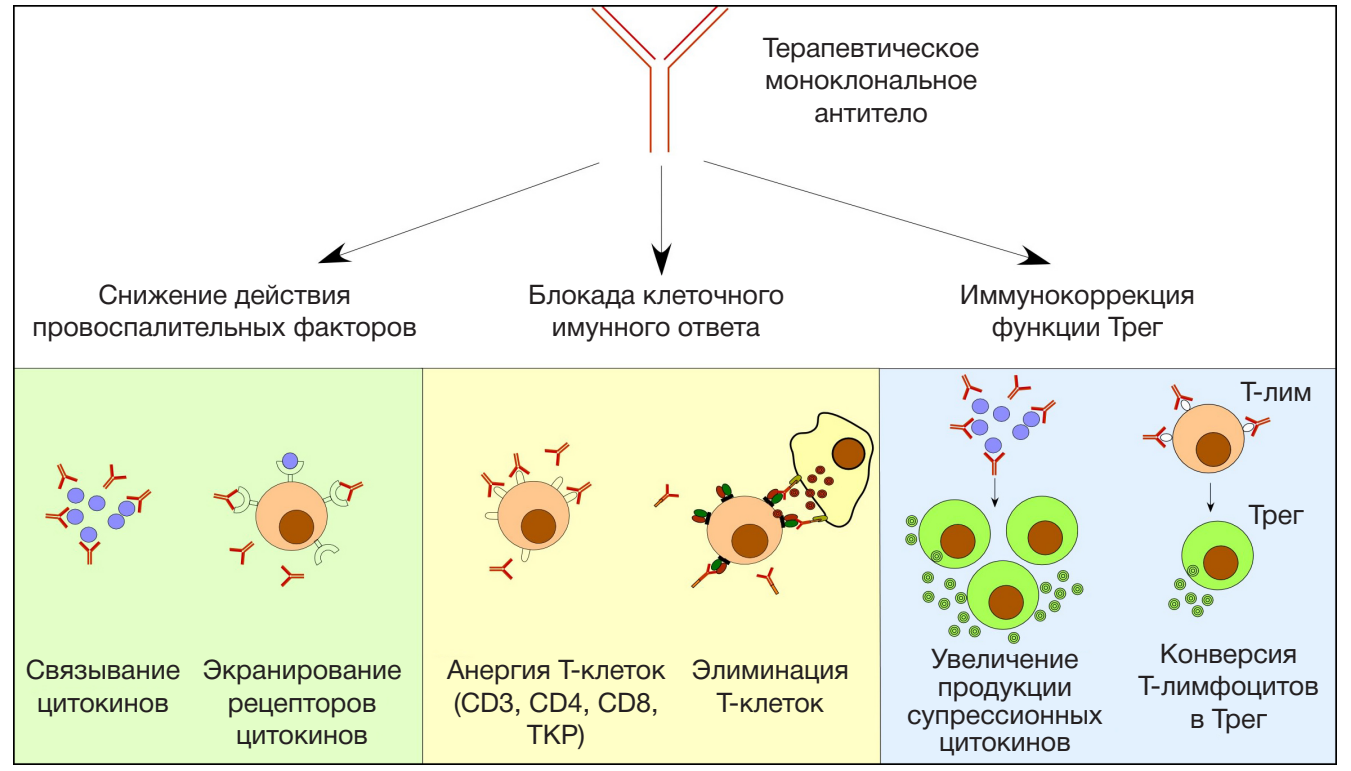

Использование моноклональных антител для терапии аутоиммунных заболеваний 
при ревматоидных аутоиммунных заболеваниях, в том числе для лечения пациентов с болезнью Бехтерева. Применение ингибиторов ФНО позволяет замедлить развитие анкилоза, но не предотвратить его. Однако не у всех пациентов можно наблюдать эффективный ответ на анти-ФНО терапию. Так, у трети людей с РА не произошло улучшения состояния, а при рассеянном склерозе терапия блокаторами ФНО оказалась неэффективной.

Использование анти-ФНО МА повышает риск возникновения онкологических и инсрекционных заболеваний. На модели экспериментального РА у мышей были получены данные о том, что блокировка ФНО не приводит к снижению уровня IL1, который активно вовлечен в процессы деструкции хрящевой ткани и эрозии суставов [5].

Провоспалительный цитокин IL1 тоже служит мишенью для направленной терапии. Но, на наш взгляд, использование антител против IL1 не может иметь широкого применения, В отличие от анакинра (anakinra) - антагониста IL1-рецептора. Так, препарат гевокизумаб (gevokizumab), MA против IL1ß, был признан неэффективным для лечения неинфекционных увеитов при болезни Бехчета. В то же время недавно была проведена III фаза клинических испытаний полностью человеческого MA против IL1ß, канакинумаба (IgG1, canakinumab) [6]. B ходе испытаний на терапию ответили менее половины пациентов с РА и ювенильным идиопатическим артритом (ЮИА) [7]. Тем не менее препарат был разрешен FDA для лечения ЮИА, а также некоторых аутовоспалительных синдромов (сryopyrin-associated periodic syndrome (CAPS)). У 97\% пациентов с CAPS уже после однократного введения препарата развивалась полная и стойкая ремиссия на фоне незначительных побочных эсрфектов [8, 9].

Другой эффективной стратегией лечения аутоиммунных заболеваний является блокировка цитокинов, которые вовлечены в активацию или дифференцировку популяций Th1- и Th17-лимфоцитов, ассоциированных с патогенезом многих аутоиммунных болезней. К таким провоспалительным факторам относится IL6, который в совокупности с IL23 и TGF $\beta$ запускает дифференцировку наивных CD4+-лимфоцитов в Th17-клетки [10]. В норме Th17-клетки участвуют в иммунном ответе на бактериальные и грибковые инфекции, но чрезмерная активность Th17, которая выражается в виде суперпродукции IL17, GM-CSF, IL21, вызывает воспаление. Нарушение баланса Th17/ Treg наблюдается при системной волчанке (systemic lupus erythematosus, SLE), в периферической крови пациентов с PA, в местах воспаления при ЮИА, при диабете 1-го типа и болезни Крона [11, 12].

К одним из эффективных препаратов, блокирующих действие IL6, относится тоцилизумаб (IgG1, tocilizumab). Это моноклональное антитело к $\beta$-цепи рецептора IL6, действие которого обусловлено конкурентным связыванием с рецептором и экранированием места посадки IL6. Доказаны его высокая эффективность и безопасность при лечении РА и ЮИА. С такой же эффективностью работает гуманизированное антитело олокизумаб (olokizumab) против самого цитокина IL6, прошедшее в 2017 г. II фазу клинических испытаний, для терапии PA.

Блокировка IL6 как на мышиной модели EAE, так и у пациентов с РА, приводит к увеличению процентной доли Tregs в популяции $\mathrm{CD}^{+}-$-лимфоцитов, что коррелирует с выраженной ремиссией у пациентов и является следствием воздействия препарата тоцилизумаб [13]. Tакое действие MA против IL6 связано с тем, что IL6 вызывает метилирование промотора Foхр3, в результате чего снижается функциональная активность Tregs [14]. B норме IL6 играет важную роль в иммунном ответе организма на бактериальные инфекции, кроме того, обладает защитными свойствами при травмах печени и нервной ткани. При долгом приеме MA против IL6 могут возрасти чувствительность организма к бактериальным и вирусным инфекциям, а также риск смертельного исхода у людей с циррозом печени и при инсультах.

Применение МА, блокирующих интерлейкины и их рецепторы, может быть более эффективным, чем лечение метотрексатом или другими иммунодепрессантами, но ассоциировано с рядом нежелательных побочных эффектов (инфекционными заболеваниями, фрарингитами и др.). Описанные выше препараты снимают симптомы заболевания, в некоторых случаях значительно замедляют его развитие, однако не устраняют причину возникновения болезни и приводят лишь к временной ремиссии.

\section{Блокада клеточного ответа}

Ингибирование аутоиммунной реакции на клеточном уровне осуществляется с помощью МА, специфично узнающих уникальные рецепторы, выделяющие определенные клеточные популяции (CD2, CD3, CD4, CD8, CD19, CD20, CD22). Данная стратегия, однако, ведет к ингибированию целой популяции лимсоцитов, затрагивая в большой степени нормально функционирующий клеточный компартмент, и приводит к значительной иммуносупрессии.

\section{$C D 3$}

Использование MA против CD3, в модельных мышиных системах аутоиммунных заболеваний, таких как аутоиммунный энцефалит, TNP-KLH-индуцированный колит, коллаген-индуцированный артрит, показало хорошие результаты. Для объяснения появления терапевтического эффекта MA против CD3 было предложено несколько не противоречащих друг другу механизмов. МА анти-CD3 связывает ६-субъединицу CD3, после чего CD3-комплекс интернализуется или экранируется. В результате Т-клетка временно перестает отвечать на представляемые ей антигены. Было также показано, что это антитело вызывает апоптоз активированных Т-клеток [15].

Применение таких MA, как теплизумаб (teplizumab) и отеликсизумаб (ChAglyCD3, otelixizumab), способствовало временной приостановке гибели продуцирующих инсулин ß-клеток при диабете 1-го типа [16]. Проходит III фаза клинических испытаний (TrialNet) теплизумаба для профилактики диабета, в которой участвуют более 500 человек со 2-й стадией диабета.

\section{Недеплецирующие антитела к CD4 и CD8}

Недавно появились работы, в которых показано использование недеплецирующих моноклональных антител к корецепторам иммунного ответа CD4 и CD8. Их эффективность была показана в отношении диабета 1-го типа в модельной мышиной системе [17]. В основе действия МА лежит специфичное взаимодействие с поверхностным рецептором лимсоцита, которое препятствует активации иммунного ответа. Отсутствие деплецирующего эффекта связано с тем, что Fс-фррагмент MA не способен связываться с Fс-рецептором реципиента 
и, соответственно, Оно не вызывает гибели клетки. В описанном эксперименте у мышей, получавших МА наблюдалась длительная ремиссия (более 200 дней), в течение которой снизилась супер-продукция цитокинов: IL2 и IFNy.

\section{Анти-CD20}

Высокоэффективным в отношении некоторых аутоиммунных заболеваний, например аутоиммунных васкулитов, антифосфолипидного синдрома, миастении, РА, системной волчанки и рассеянного склероза, оказался препарат на основе MA к CD20 ритуксимаб (rituximab, мабтера). Эфффект препарата, заключающийся в деплеции В-клеток, длится временно (в среднем 6 месяцев). Терапия ритуксимабом у многих пациентов имела отложенный эффеект: ответ мог наблюдаться через несколько месяцев после введения препарата. Предложено несколько объяснений: 1) скорость выведения В-клеток из организма может варьировать от пациента к пациенту; 2) время полужизни плазматической клетки может влиять на скорость ответа, так как она не несет CD20 на поверхности и продолжает секретировать антитела; 3) у некоторых пациентов аутоиммунные антитела могут приводить к патологизации даже в очень низких концентрациях, что может отсрочить ответ на терапию, пока антитела не будут выведены. Эффективность ритуксимаба оценивается как такая же, а в некоторых случаях даже выше, чем эффективность химических иммунодепрессантов (циклофосфрамида, азотиоприна и др.). Однако длительная ремиссия наблюдается только у 20\% пациентов. В качестве побочных эффектов описаны повышенная чувствительность к различным инфекциям, гипогаммаглобулинемия, нейтрофилопения [18, 19]. Стоит отметить, что препарат назначали при тяжелых формах РА в тех случаях, когда базисная терапия (глюкокортикоидная и цитотоксическая) не давала положительного эффекта. Одно из возможных объяснений действия ритуксимаба при РА может заключаться в том, что помимо деплеции В-клеток элиминируются также CD20+-Th17-эффекторные клетки, процент которых достаточно высок в крови пациентов с PA [20]. Другой механизм действия анти-CD20-терапии заключается в том, что В-клетки также могут активно продуцировать IL6, который приводит к дифференцировке предшественников Т-клеток в Th17 и блокирует созревание предшественников в Treg $[21,22]$. Гуманизированное MA анти-CD20 окрелизумаб (ocrelizumab) прошло клинические испытания и одобрено FDA для лечения рассеянного склероза; при его приеме показано значимое снижение очагов поражения и замедление развития заболевания [23].

\section{Иммунокоррекция: «перепрограммирование» Т-лимфоцитов в Tregs}

Клетки Treg обеспечивают толерантность на периферии, т. е. «заглушают» иммунный ответ и соответственно останавливают аутоиммунные реакции [24]. Они секретируют ингибирующие воспаление цитокины IL10, TGFß, IL35, индуцируют гранзим/перфориновый апоптоз эффекторных клеток, ингибируют функции дендритных клеток. С одной стороны, одним из подходов к лечению аутоиммунных заболеваний можно считать увеличение Treg в крови, либо к увеличению суперпродукции супрессионных цитокинов. С другой стороны, высокая активность Treg ведет к супрессии иммунного ответа и способствует злокачественному росту. В 2016 г. опробирован препарат трегализумаб (tregalizumab), недеплецирующее MA, которое связывает уникальный эпитоп на молекуле CD4, в результате чего CD4+-лимфоциты дифрференцируются в Treg.

Предпочтительной стратегией при лечении аутоиммунных заболеваний, по нашему мнению, может быть комбинированная терапия, включающая таргетную элиминацию Т- или В-клеточных клонов, ассоциированных с аутоиммунными процессами. Такая терапия может сочетать последовательное применение нескольких биологиксов, воздействующих на различные звенья иммунного ответа. Например, в качестве первой линии было предложено использовать цитокиновые блокаторы или MA, деплецирующие патогенные клеточные популяции, а в качестве второй линии - агенты, блокирующие медиаторы CD28 костимуляции или ингибирующие гомеостатические цитокины [25]. Недавно проведенные исследования показывают, что ингибирование таких гомеостатических цитокинов, как IL15, IL7, может оказаться перспективным подходом к терапии аутоиммунных заболеваний [26].

До настоящего времени не решена проблема идентификации уникальных маркеров аутоиммунного воспаления. Такими маркерами могут служить Т- и В-клеточные рецепторы (ТKР и ВКР) на поверхности аутоиммунных лимсоцитов. Секвенирование репертуаров ТКР и ВКР лимфоцитов периферической крови, а также лимфоцитов, выделенных из области воспаления, и последующий сравнительный анализ репертуаров здоровых и больных доноров - это пути к решению задачи по поиску сцепленных с заболеванием иммунных рецепторов. На сегодняшний день удалось установить структуру потенциально аутоиммунных ТКР для двух заболеваний: целиакии и анкилозирующего спондилита [27-29]. Так, нашим научным коллективом получена структура ТKР, ассоциированного с анкилозирующим спондилитом [28], которая была независимо подтверждена результатами исследования, проведенного английскими коллегами [29]. Патологический Т-клеточный клон содержит вариабельный генный сегмент TRBV9. Мы получили MA, специфично узнающие и деплецирующие in vitro Т-клетки, несущие на своей поверхности ТКР, ассоциированные с анкилозирующим спондилитом [30]. Описанный выше подход к разработке новых препаратов и собственно описанное нами МА, кажется нам хорошей платформой для создания новых лекарственных средств для лечения аутоиммунных заболеваний и болезни Бехтерева, в частности.

\section{ВЫВОДЫ}

Широкомасштабное массированное секвенирование иммунных репертуаров здоровых доноров и пациентов с такими тяжелыми аутоиммунными заболеваниями, как рассеянный склероз, диабет 1-го типа, а также последовательное HLA-типирование открывают возможности к идентификации новых мишеней для направленной иммунотерапии. 


\section{Литература}

1. Danke NA, Koelle DM, Yee C, Beheray S, Kwok WW. Autoreactive T cells in healthy individuals. J Immunol. 2004; (172): 5967-2.

2. Konno Y, Kobayashi Y, Takahashi K, Takahashi E, Sakae S, Wakitani $\mathrm{M}$, et al. Fucose content of monoclonal antibodies can be controlled by culture medium osmolality for high antibodydependent cellular cytotoxicity. Cytotechnology. 2012; (64): 249-65.

3. Lai $\mathrm{Y}$, Dong $\mathrm{C}$. Therapeutic antibodies that target inflammatory cytokines in autoimmune diseases. Int Immunol. 2016; (28): 181-8.

4. Nasonov EL, Denisov LN, Stanislav ML. Interleukin-17 is a new target for anti-cytokine therapy of immune inflammatory rheumatic diseases. Rheumatology Science and Practice. 2013; (51): 545.

5. van den Berg WB, Joosten LA, Kollias G, van De Loo FA. Role of tumour necrosis factor alpha in experimental arthritis: separate activity of interleukin 1 beta in chronicity and cartilage destruction. Ann Rheum Dis. 1999; 58 (Suppl 1): 140-8.

6. Dinarello CA, Simon A, van der Meer JWM. Treating inflammation by blocking interleukin-1 in a broad spectrum of diseases. Nat Rev Drug Discov. 2012; (11): 633-52.

7. Ruperto N, Brunner HI, Quartier P, Constantin T, Wulffraat NM, Horneff $G$, et al. Canakinumab in patients with systemic juvenile idiopathic arthritis and active systemic features: results from the 5-year long-term extension of the phase III pivotal trials. Ann Rheum Dis. 2018; (77): 1710-9.

8. Georgiev K, Georgieva M. Pharmacological properties of monoclonal antibodies directed against interleukins. In: Metodiev $\mathrm{K}$, editor. Immunopathology and Immunomodulation. IntechOpen; 2015; p. 261-86. DOI: 10.5772/61774.

9. Goh $A X H$, Bertin-Maghit $S$, Ping Yeo $S, H o$ AWS, Derks $H$, Mortellaro A, et al. A novel human anti-interleukin- $1 \beta$ neutralizing monoclonal antibody showing in vivo efficacy. MAbs. 2014; (6): 765-73.

10. Gaffen SL, Jain R, Garg AV, Cua DJ. The IL23-IL17 immune axis: from mechanisms to therapeutic testing. Nat Rev Immunol. 2014; (14): 585-600.

11. Tabarkiewicz J, Pogoda K, Karczmarczyk A, Pozarowski P, Giannopoulos K. The role of IL17 and Th17 lymphocytes in autoimmune diseases. Arch Immunol Ther Exp. 2015; (63): 435-49.

12. Lee GR. The Balance of Th17 versus Treg Cells in Autoimmunity. Int J Mol Sci. 2018; 19 (3): 730. DOl:10.3390/ijms19030730.

13. Kikuchi J, Hashizume M, Kaneko Y, Yoshimoto K, Nishina N, Takeuchi T. Peripheral blood CD4(+)CD25(+)CD127(low) regulatory $T$ cells are significantly increased by tocilizumab treatment in patients with rheumatoid arthritis: increase in regulatory $T$ cells correlates with clinical response. Arthritis Res Ther. 2015; (17): 10.

14. Lal G, Zhang N, van der Touw W, Ding Y, Ju W, Bottinger EP, et al. Epigenetic regulation of Foxp3 expression in regulatory $T$ cells by DNA methylation. J Immunol. 2009; (182): 259-73.

15. Kuhn C, Weiner HL. Therapeutic anti-CD3 monoclonal antibodies: from bench to bedside. Immunotherapy. 2016; (8): 889-906.

16. Guglielmi C, Williams SR, Del Toro R, Pozzilli P. Efficacy and safety of otelixizumab use in new-onset type 1 diabetes mellitus. Expert Opin Biol Ther. 2016; (16): 841-6.

\section{References}

1. Danke NA, Koelle DM, Yee C, Beheray S, Kwok WW. Autoreactive T cells in healthy individuals. J Immunol. 2004; (172): 5967-2.

2. Konno Y, Kobayashi Y, Takahashi K, Takahashi E, Sakae S, Wakitani $\mathrm{M}$, et al. Fucose content of monoclonal antibodies can be controlled by culture medium osmolality for high antibodydependent cellular cytotoxicity. Cytotechnology. 2012; (64): 249-65.

3. Lai $\mathrm{Y}$, Dong $\mathrm{C}$. Therapeutic antibodies that target inflammatory cytokines in autoimmune diseases. Int Immunol. 2016; (28): 181-8.

4. Nasonov EL, Denisov LN, Stanislav ML. Interleukin-17 is a new target for anti-cytokine therapy of immune inflammatory rheumatic diseases. Rheumatology Science and Practice. 2013; (51): 545.

5. van den Berg WB, Joosten LA, Kollias G, van De Loo FA. Role of tumour necrosis factor alpha in experimental arthritis: separate activity of interleukin 1 beta in chronicity and cartilage destruction.
17. Yi Z, Diz R, Martin AJ, Morillon YM, Kline DE, Li L et al. Long-term remission of diabetes in NOD mice is induced by nondepleting anti-CD4 and anti-CD8 antibodies. Diabetes. 2012; (61): 2871-80.

18. Randall KL. Rituximab in autoimmune diseases. Aust Prescr. 2016; (39): 131-4.

19. Looney RJ. B cells as a therapeutic target in autoimmune diseases other than rheumatoid arthritis. Rheumatology. 2005; 44 (Suppl 2): ii13-ii17.

20. Mélet J, Mulleman D, Goupille P, Ribourtout B, Watier H, Thibault G. Rituximab-induced T cell depletion in patients with rheumatoid arthritis: association with clinical response. Arthritis Rheum. 2013; (65): 2783-90.

21. Barr TA, Shen P, Brown S, Lampropoulou V. B cell depletion therapy ameliorates autoimmune disease through ablation of IL-6-producing B cells. J Exp Med. 2012; 209 (5): 1001-10. DOI: 10.1084/jem.20111675.

22. Korn T, Mitsdoerffer M, Croxford AL, Awasthi A, Dardalhon VA, Galileos $G$ et al. IL6 controls Th17 immunity in vivo by inhibiting the conversion of conventional $\mathrm{T}$ cells into Foxp3+ regulatory $\mathrm{T}$ cells. Proc Natl Acad Sci USA. 2008; (105): 18460-5.

23. Mulero P, Midaglia L, Montalban X. Ocrelizumab: a new milestone in multiple sclerosis therapy. Ther Adv Neurol Disord. 2018; (11): 1756286418773025. DOI: 10.1177/1756286418773025.

24. König $M$, Rharbaoui $F$, Aigner $S$, Dälken $B$, Schüttrumpf J. Tregalizumab - A Monoclonal Antibody to Target Regulatory $\mathrm{T}$ Cells. Front Immunol. 2016; (7): 11

25. Smilek DE, Ehlers MR, Nepom GT. Restoring the balance: immunotherapeutic combinations for autoimmune disease. Dis Model Mech. 2014; (7): 503-13.

26. Chen Y, Chauhan SK, Tan X, Dana R. Interleukin-7 and -15 maintain pathogenic memory Th17 cells in autoimmunity. $J$ Autoimmun. 2017; (77): 96-103.

27. Yohannes DA, Freitag TL, de Kauwe A, Kaukinen K, Kurppa K, Wacklin $\mathrm{P}$ et al. Deep sequencing of blood and gut T-cell receptor $\beta$-chains reveals gluten-induced immune signatures in celiac disease. Sci Rep. 2017; (7): 17977.

28. Komech EA, Pogorelyy MV, Egorov ES, Britanova OV, Rebrikov DV, Bochkova AG et al. CD8 ${ }^{+} T$ cells with characteristic T cell receptor beta motif are detected in blood and expanded in synovial fluid of ankylosing spondylitis patients. Rheumatology. 2018; (57): 1097104.

29. Faham M, Carlton V, Moorhead M, Zheng J, Klinger M, Pepin F et al. Discovery of T Cell Receptor $\beta$ Motifs Specific to HLA--B27-Positive Ankylosing Spondylitis by Deep Repertoire Sequence Analysis. Arthritis \& Rheumatology. Wiley Online Library; 2017; (69): 774-84.

30. Израельсон М. А., Степанов А. В., Староверов Д. Б., Шагина И. А., Мисорин А. К., Евстратьева А. В. и др. Тестирование моноклональных антител к Т-клеточному рецептору, ассоциированному с анкилозирующим спондилитом. Вестник РГМУ. 2018; (5): 83-92. DOI: 10.24075/vrgmu.2018.064.

Ann Rheum Dis. 1999; 58 (Suppl 1): 140-8.

6. Dinarello CA, Simon A, van der Meer JWM. Treating inflammation by blocking interleukin-1 in a broad spectrum of diseases. Nat Rev Drug Discov. 2012; (11): 633-52.

7. Ruperto N, Brunner HI, Quartier P, Constantin T, Wulffraat NM, Horneff G, et al. Canakinumab in patients with systemic juvenile idiopathic arthritis and active systemic features: results from the 5 -year long-term extension of the phase III pivotal trials. Ann Rheum Dis. 2018; (77): 1710-9.

8. Georgiev K, Georgieva M. Pharmacological properties of monoclonal antibodies directed against interleukins. In: Metodiev $\mathrm{K}$, editor. Immunopathology and Immunomodulation. IntechOpen; 2015; p. 261-86. DOI: 10.5772/61774.

9. Goh AXH, Bertin-Maghit S, Ping Yeo S, Ho AWS, Derks $H$, 
Mortellaro A, et al. A novel human anti-interleukin-1 $\beta$ neutralizing monoclonal antibody showing in vivo efficacy. MAbs. 2014; (6): 765-73.

10. Gaffen SL, Jain R, Garg AV, Cua DJ. The IL23-IL17 immune axis: from mechanisms to therapeutic testing. Nat Rev Immunol. 2014 (14): 585-600.

11. Tabarkiewicz J, Pogoda K, Karczmarczyk A, Pozarowski P, Giannopoulos K. The role of IL17 and Th17 lymphocytes in autoimmune diseases. Arch Immunol Ther Exp. 2015; (63): 435-49.

12. Lee GR. The Balance of Th17 versus Treg Cells in Autoimmunity. Int J Mol Sci. 2018; 19 (3): 730. DOl:10.3390/ijms19030730.

13. Kikuchi J, Hashizume M, Kaneko Y, Yoshimoto K, Nishina N, Takeuchi T. Peripheral blood CD4(+)CD25(+)CD127(low) regulatory $\mathrm{T}$ cells are significantly increased by tocilizumab treatment in patients with rheumatoid arthritis: increase in regulatory $\mathrm{T}$ cells correlates with clinical response. Arthritis Res Ther. 2015; (17): 10

14. Lal G, Zhang N, van der Touw W, Ding Y, Ju W, Bottinger EP, et al. Epigenetic regulation of Foxp3 expression in regulatory $T$ cells by DNA methylation. J Immunol. 2009; (182): 259-73.

15. Kuhn C, Weiner HL. Therapeutic anti-CD3 monoclonal antibodies: from bench to bedside. Immunotherapy. 2016; (8): 889-906.

16. Guglielmi C, Williams SR, Del Toro R, Pozzilli P. Efficacy and safety of otelixizumab use in new-onset type 1 diabetes mellitus. Expert Opin Biol Ther. 2016; (16): 841-6.

17. Yi Z, Diz R, Martin AJ, Morillon YM, Kline DE, Li L et al. Long-term remission of diabetes in NOD mice is induced by nondepleting anti-CD4 and anti-CD8 antibodies. Diabetes. 2012; (61): 2871-80.

18. Randall KL. Rituximab in autoimmune diseases. Aust Prescr. 2016; (39): 131-4.

19. Looney RJ. B cells as a therapeutic target in autoimmune diseases other than rheumatoid arthritis. Rheumatology. 2005; 44 (Suppl 2): ii13-ii17.

20. Mélet J, Mulleman D, Goupille P, Ribourtout B, Watier H, Thibault G. Rituximab-induced $T$ cell depletion in patients with rheumatoid arthritis: association with clinical response. Arthritis Rheum. 2013; (65): 2783-90.

21. Barr TA, Shen P, Brown S, Lampropoulou V. B cell depletion therapy ameliorates autoimmune disease through ablation of
IL-6-producing B cells. J Exp Med. 2012; 209 (5): 1001-10. DOI: 10.1084/jem.20111675.

22. Korn T, Mitsdoerffer M, Croxford AL, Awasthi A, Dardalhon VA Galileos $\mathrm{G}$ et al. IL6 controls Th17 immunity in vivo by inhibiting the conversion of conventional T cells into Foxp3+ regulatory $T$ cells. Proc Natl Acad Sci USA. 2008; (105): 18460-5.

23. Mulero P, Midaglia L, Montalban X. Ocrelizumab: a new milestone in multiple sclerosis therapy. Ther Adv Neurol Disord. 2018; (11): 1756286418773025. DOl: 10.1177/1756286418773025.

24. König M, Rharbaoui F, Aigner S, Dälken B, Schüttrumpf J. Tregalizumab - A Monoclonal Antibody to Target Regulatory T Cells. Front Immunol. 2016; (7): 11.

25. Smilek DE, Ehlers MR, Nepom GT. Restoring the balance: immunotherapeutic combinations for autoimmune disease. Dis Model Mech. 2014; (7): 503-13.

26. Chen $Y$, Chauhan SK, Tan $X$, Dana R. Interleukin-7 and -15 maintain pathogenic memory Th17 cells in autoimmunity. J Autoimmun. 2017; (77): 96-103.

27. Yohannes DA, Freitag TL, de Kauwe A, Kaukinen K, Kurppa K, Wacklin $P$ et al. Deep sequencing of blood and gut T-cell receptor $\beta$-chains reveals gluten-induced immune signatures in celiac disease. Sci Rep. 2017; (7): 17977.

28. Komech EA, Pogorelyy MV, Egorov ES, Britanova OV, Rebrikov DV, Bochkova AG et al. CD8 ${ }^{+}$T cells with characteristic T cell receptor beta motif are detected in blood and expanded in synovial fluid of ankylosing spondylitis patients. Rheumatology. 2018; (57): 1097104.

29. Faham M, Carlton V, Moorhead M, Zheng J, Klinger M, Pepin F et al. Discovery of $T$ Cell Receptor $\beta$ Motifs Specific to HLA--B27-Positive Ankylosing Spondylitis by Deep Repertoire Sequence Analysis. Arthritis \& Rheumatology. Wiley Online Library; 2017; (69): 774-84.

30. Israelson MA, Stepanov AV, Staroverov DB, Shagina IA, Misorin AK, Evstratieva AV, Merzlyak EM, Bogdanova EA, Britanova OV, Lukyanov SA. Testing of monoclonal antibodies against the T-cell receptor associated with ankylosing spondylitis. Bulletin of RSMU. 2018; (5): 71-9. DOI: 10.24075/brsmu.2018.064. 